September 2004 - NREL/TP-500-36371

\title{
Motion Technologies CRADA CRD-03-130: Assessing the Potential of a Mechanical Continuously Variable Transmission
}

\author{
J. Cotrell
}

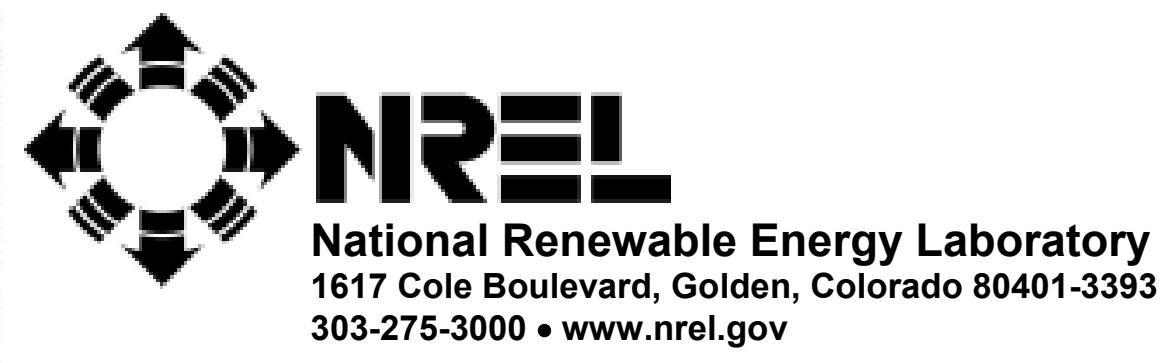

Operated for the U.S. Department of Energy Office of Energy Efficiency and Renewable Energy by Midwest Research Institute • Battelle 


\title{
Motion Technologies CRADA CRD-03-130: Assessing the Potential of a Mechanical Continuously Variable Transmission
}

\author{
J. Cotrell
}

Prepared under Task No. WER4 3202

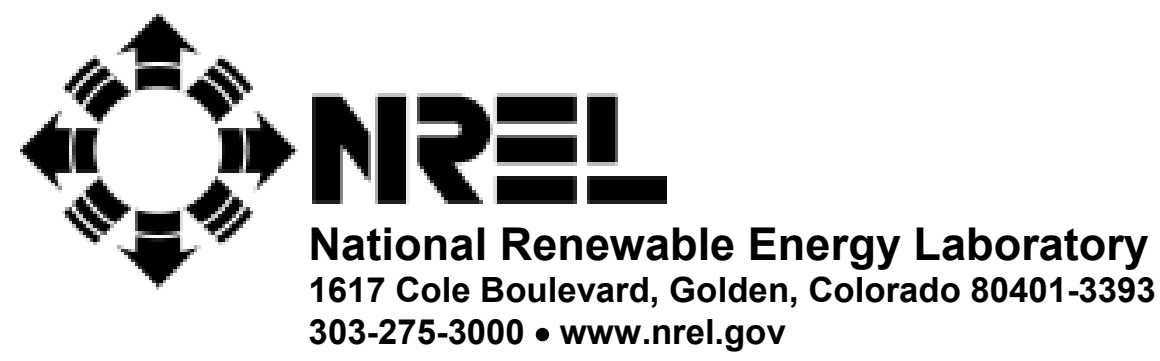

Operated for the U.S. Department of Energy Office of Energy Efficiency and Renewable Energy by Midwest Research Institute • Battelle Contract No. DE-AC36-99-GO10337 


\section{NOTICE}

This report was prepared as an account of work sponsored by an agency of the United States government. Neither the United States government nor any agency thereof, nor any of their employees, makes any warranty, express or implied, or assumes any legal liability or responsibility for the accuracy, completeness, or usefulness of any information, apparatus, product, or process disclosed, or represents that its use would not infringe privately owned rights. Reference herein to any specific commercial product, process, or service by trade name, trademark, manufacturer, or otherwise does not necessarily constitute or imply its endorsement, recommendation, or favoring by the United States government or any agency thereof. The views and opinions of authors expressed herein do not necessarily state or reflect those of the United States government or any agency thereof.

Available electronically at http://www.osti.gov/bridge

Available for a processing fee to U.S. Department of Energy and its contractors, in paper, from:

U.S. Department of Energy

Office of Scientific and Technical Information

P.O. Box 62

Oak Ridge, TN 37831-0062

phone: 865.576.8401

fax: 865.576.5728

email: mailto:reports@adonis.osti.gov

Available for sale to the public, in paper, from:

U.S. Department of Commerce

National Technical Information Service

5285 Port Royal Road

Springfield, VA 22161

phone: 800.553 .6847

fax: 703.605.6900

email: orders@ntis.fedworld.gov

online ordering: http://www.ntis.gov/ordering.htm 


\section{Table of Contents}

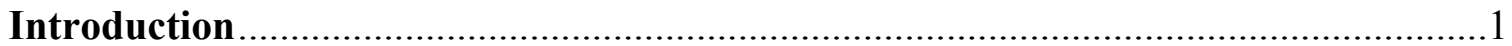

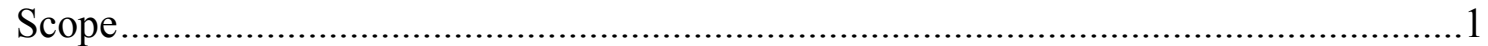

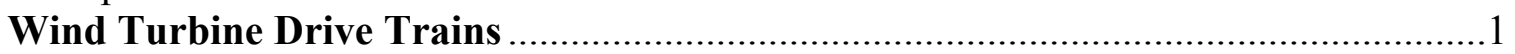

Variable Speed Theory ............................................................................................ 1

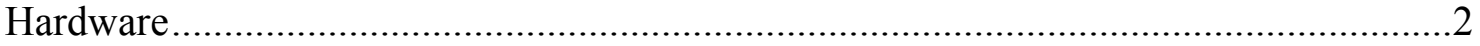

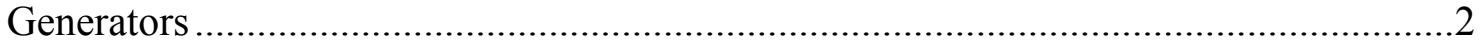

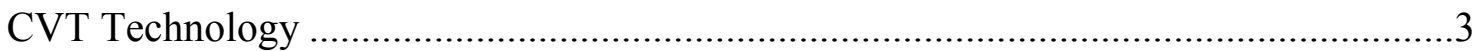

CVT Advantages...................................................................................................

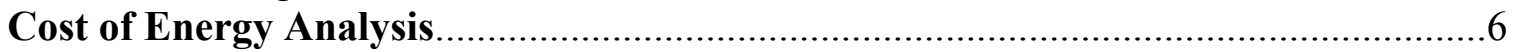

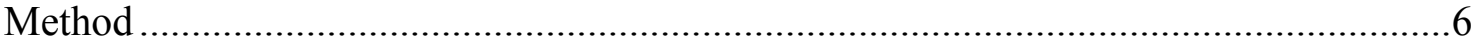

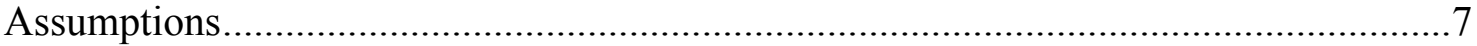

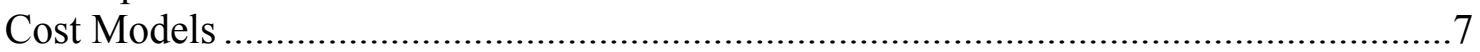

Performance Models ............................................................................................... 7

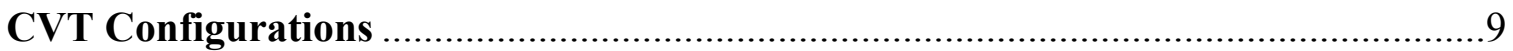

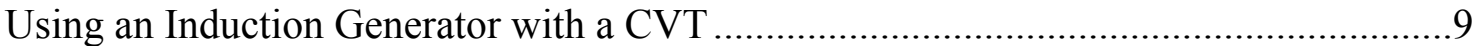

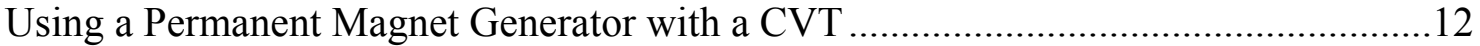

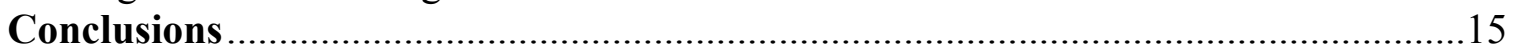

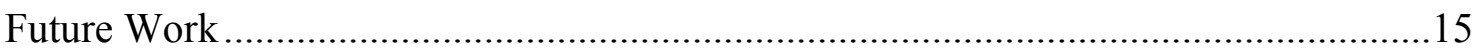

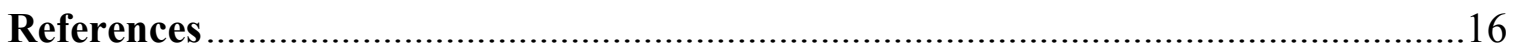

\section{List of Figures}

Figure 1. Exploded view of motion CVT variator with core components........................4

Figure 2. Motion CVT design with two variators ...................................................

Figure 3. WindPACT power curve and rpm curve for a 1.5-MW turbine........................6

Figure 4. Modular, integrated, and PM baseline configurations........................................8

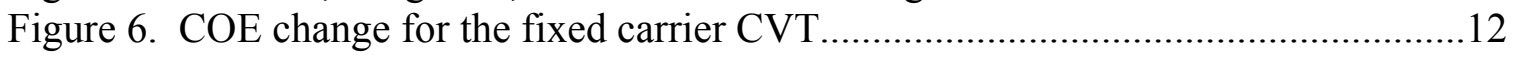

Figure 7. Reduction in COE for the fixed carrier output ...........................................15

\section{List of Tables}

Table 1. CVT Efficiency Data from Motion Technologies Inc......................................9

Table 2. Squirrel Cage CVT Results with an Integrated Mainframe..............................11

Table 3. CVT Results with a PM Generator, Single Stage Gearbox, and

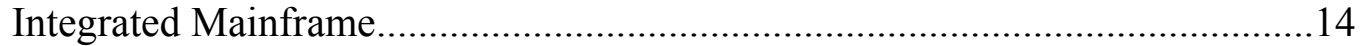




\section{Introduction}

This report summarizes the results of a cooperative research and development agreement (CRADA) between the National Renewable Energy Laboratory (NREL) and Motion Technologies LLC. The purpose of the CRADA is to assess the usefulness of a continuously variable transmission (CVT) for wind turbine applications. The CVT considered is capable of rapid ratio changes and may be directly applicable to variable speed wind turbine designs. This approach potentially offers a less expensive mechanical alternative to the use of power electronics (PE) currently used in large and small machines for variable speed operation.

According to Motion Technologies, the CVT is the first continuously variable transmission that is scalable to the torque capacities required in large wind turbine applications. The CVT technology was examined for potential economic and performance benefits when integrated into conventional wind turbine designs. This report is the first step in assessing the practicality of using CVT technology in variable speed wind turbines.

\section{Scope}

Several questions were raised at the start of this CRADA:

1. What is the most economical combination of CVT ratio and gearbox ratio?

2. How much can CVT technology reduce the cost of energy (COE) for modern wind turbines?

3. Does the CVT eliminate or limit the need for variable speed electronics?

4. Does the CVT enable the use of more cost-effective generator and PE technologies?

5. What generator types can be used with a CVT, and what are the implications?

6. Does the CVT enable useful operation of the turbine at lower wind speeds than are presently practical?

To address these questions, NREL performed economic and performance analyses. The WindPACT 1.5-MW wind turbine was used as a baseline design [1]. We determined the COE differences from the baseline by replacing the WindPACT drive train with a CVT drive train scaled to 1.5 MW. NREL used CVT efficiency curves furnished by Motion Technologies to perform the analysis.

\section{Wind Turbine Drive Trains}

\section{Variable Speed Theory}

There are several advantages of using variable speed technology on wind turbines. This section briefly describes the motivations for and the principle of variable speed technology. A thorough treatment of variable speed can be found in Carlin et al. [2]. 
One of the primary advantages of a variable speed wind turbine compared to a constantspeed wind turbine is its ability to increase the amount of electricity generated by operating at a higher aerodynamic efficiency. The aerodynamic efficiency of a wind turbine rotor varies with the tip speed ratio of the rotor (the speed of the blade tip divided by the wind speed at hub height). Wind turbines typically have a peak aerodynamic efficiency at a tip speed ratio somewhere between 5 and 8 . Thus, the optimum aerodynamic efficiency occurs when the blade tip speed is 5 to 8 times the speed of the wind. In contrast to a constant-speed wind turbine, a variable speed turbine can operate at the optimum tip speed ratio over a range of wind speeds. That is, if the winds blow faster, the rotor speed is increased to maintain the optimum tip speed ratio.

A second advantage of a variable speed turbine is its ability to alleviate fatigue loads caused by gusts. Power produced by large wind turbines is typically regulated by pitching the blades. Gusts can create large torque spikes on a wind turbine drive train if the turbine is unable to respond quickly enough by pitching the blades. A variable speed turbine can operate in a manner that can quickly absorb this excess power. A large portion of the energy from the gust can be consumed in the inertia of the rotor by allowing the rotor speed to increase a mere $3 \%$ to $5 \%$ above the nominal operating speed. This speed increase gives the pitch system time to pitch the blades to reduce the torque and speed generated by the rotor.

\section{Hardware}

A variable speed design normally incorporates advanced PE components that increase overall turbine cost. These components are required to change variable AC power to constant voltage and frequency.

Most modern variable speed machines use wound-rotor, doubly fed induction generators. They obtain variable speed operation by changing the electrical frequency of the rotor with PE. The rotor PE is sized so that it can accept the slip power (about one-third of the turbine's rated power). The remainder of the power flows through the stator, which is connected directly to the grid. To reduce the amount of slip and PE needed, the speed range of these machines is narrowed so that the turbine operates in a constant-speed mode during very slow winds.

\section{Generators}

Hau [3] presents an overview of wind turbine generator technologies. This section presents selected ideas from his book to provide a basic understanding of the importance of generator options to be used with the CVT.

\section{Induction Generators}

Wind turbine generators can be classified as synchronous or induction machines. Both have the same basic stator winding design. In induction machines, an electric field is induced between the rotor and the rotating stator field by a relative motion that causes a current in the rotor windings. This relative motion is called slip. The current cause a magnetic field that interacts with the stator field to produce torque. 
The rotor of an induction machine can be designed as a so-called squirrel cage rotor or as a wound rotor. The squirrel cage rotor is advantageous because of its simplicity and lower cost. However, the more complex wound rotor allows the electrical characteristics of the rotor, such as the amount of slip, to be changed from outside the generator by using sliprings. Variable speed can be achieved in the wound rotor generator with a frequency converter to control the electrical frequency of the rotor. In this so-called doubly fed generator, speed variations of any size are possible but are typically approximately $40 \%$ of the nominal speed to reduce the amount of power electronics required.

\section{Synchronous Generators}

Synchronous generators can be made with a wound rotor or a permanent magnet (PM) rotor. One advantage of synchronous generators is that they tend to be slightly more efficient than induction generators because they have no slip. An advantage of a PM machine over the wound rotor machine is its simplicity—-there are no slip rings or rotor windings.

Because synchronous generators have no slip, they must be decoupled from the grid to prevent dynamic loads caused by strong gusts from damaging the drive train. This decoupling is typically achieved with an AC-DC-AC link. The variable frequency AC from the generator is rectified into $\mathrm{DC}$ and fed into the grid via an $\mathrm{AC}$ inverter.

\section{CVT Technology}

Currently several CVT technologies - including hydro-mechanical, variable pulleys (which use either a belt or a chain), and rolling traction transmissions - are in some state of production or development. Rolling traction transmissions use one or more components that allow variation of the input and output rolling diameters. These components are typically torroids, discs, cones, or balls. The present technologies all have inherent limitations in terms of either scalability to the wind turbine application or efficiency (or both). The Motion CVT is a new type of rolling traction transmission that uses balls to vary speed. A brief description of Motion Technologies CVT follows. 
Figure 1 is an exploded view of a Motion Technologies CVT variator. The variator is the transmission component that allows smooth, continuous transition between an infinite number of gear ratios.

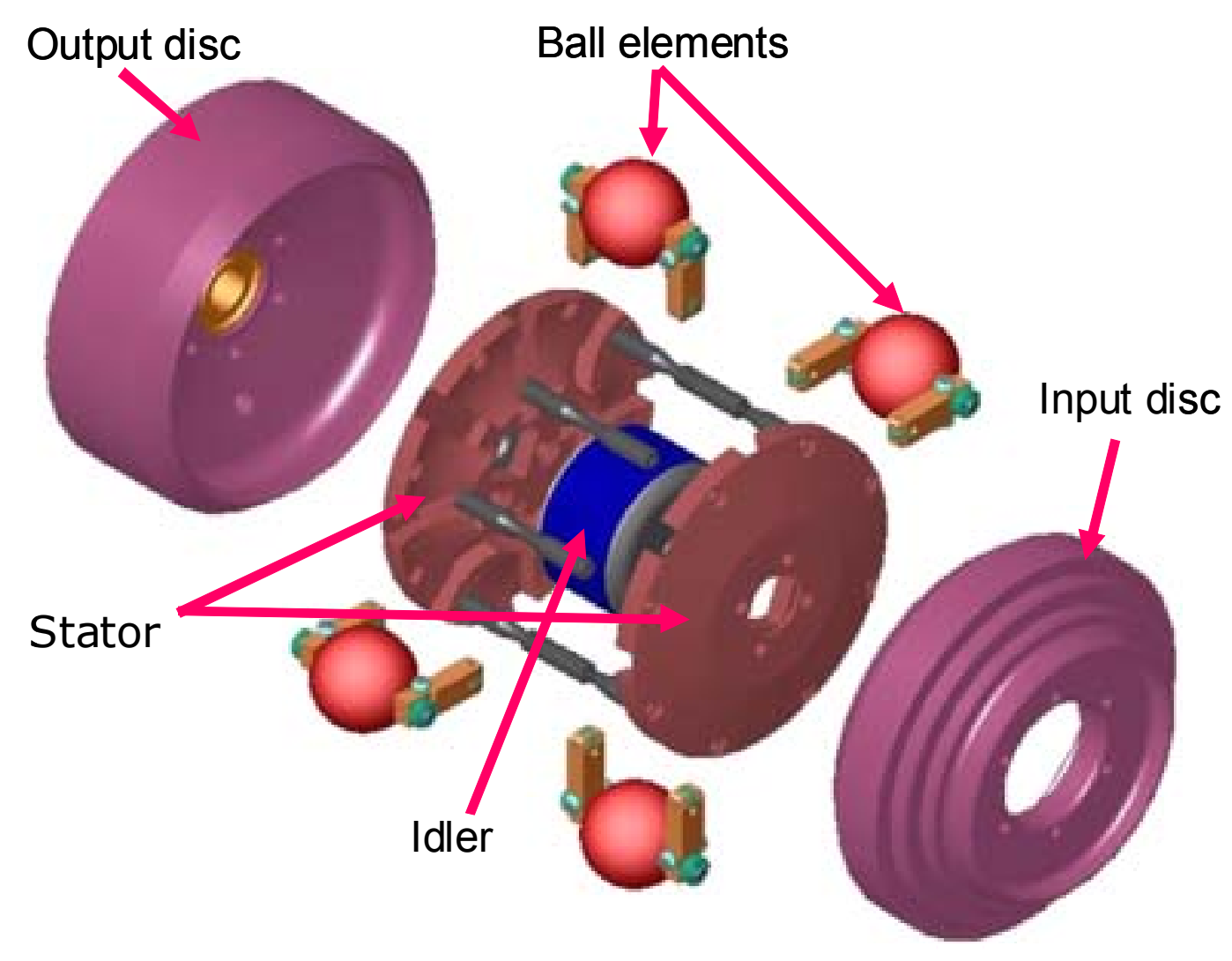

Figure 1. Exploded view of Motion CVT variator with core components

The variator transfers power between an input disc and an output disc. The balls transmit power from the input disc to the output disc using elastohydrodynamic lubrication. The transmission ratio is changed by varying the angle of the balls' rotational axes. In the configuration in Figure 1, this angle is changed by moving the idler along the longitudinal axis of the CVT. The Motion CVT uses 3 to 20 balls, depending on the torque capacity desired. For a given diameter of the Motion CVT, a greater number of balls provides a greater torque capacity. This scaling characteristic is commonly employed with conventional planetary gears, but it is unique to the Motion CVT among present technology continuously variable transmissions. Other CVTs cannot be scaled up in torque capacity so easily, and this characteristic makes the Motion CVT potentially viable for the wind turbine application.

Figure 2 is a cutaway of a Motion CVT that uses two variator cavities. This design doubles the torque capacity of the CVT without increasing its diameter. This design may be advantageous for wind turbines because of their high torque requirements. The dual cavity design also has positive implications for throughput efficiency of the CVT, but a detailed technical treatment is beyond the scope of this report. 


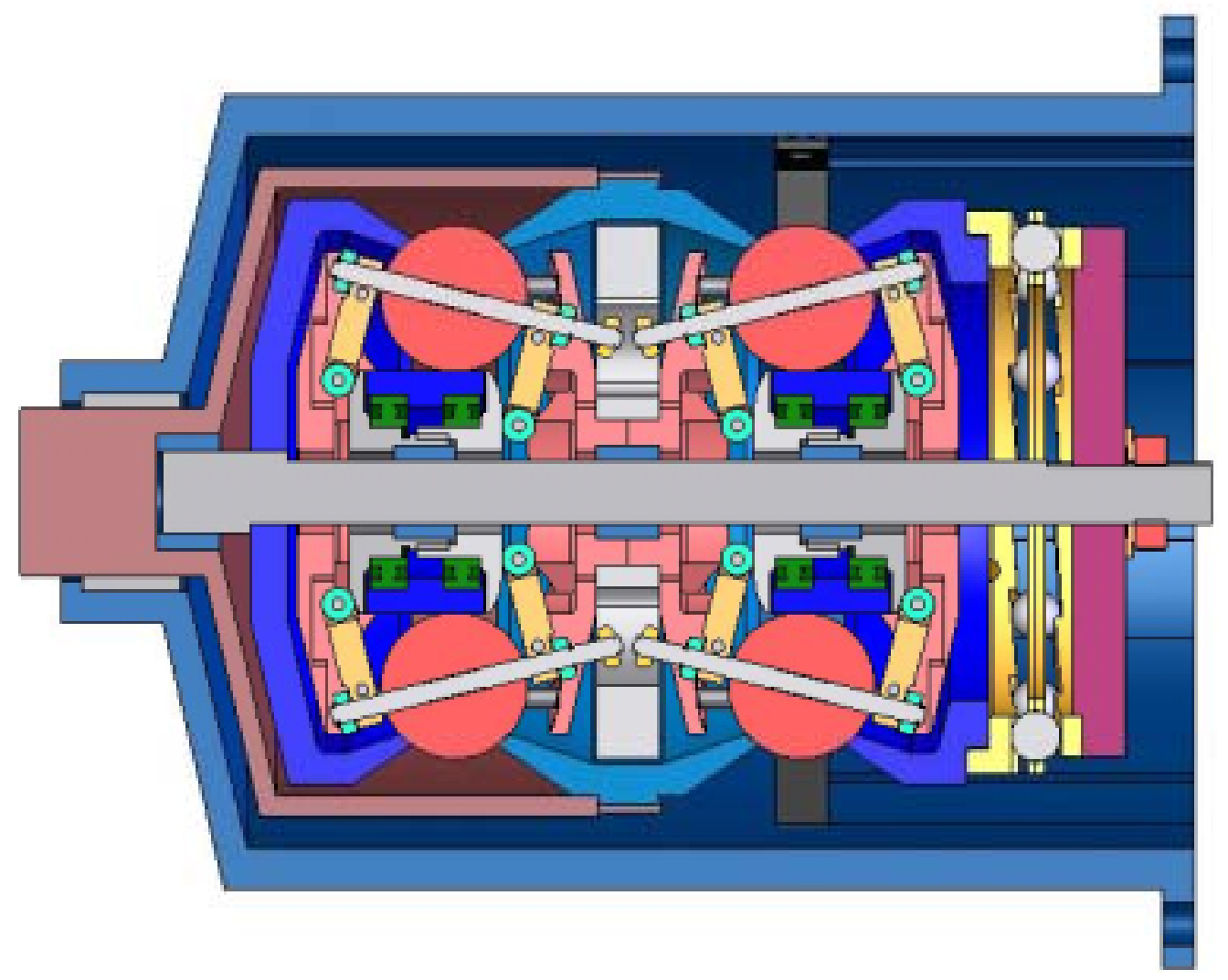

Figure 2. Motion CVT design with two variators

\section{CVT Advantages}

There are several advantages of using CVTs on wind turbines. One is the possibility of a wider range of variable speed than the conventional doubly fed solution.

For example, in the baseline turbine of the WindPACT Advanced Drive train study, the cutin (startup) wind speed is $3.0 \mathrm{~m} / \mathrm{s}(\sim 7 \mathrm{mph})$. The wind turbine rotor speed remains at $12.3 \mathrm{rpm}$ until the wind speed reaches $6.5 \mathrm{~m} / \mathrm{s}$. Then the rpm increases linearly with wind speed until the machine reaches rated power at $19 \mathrm{rpm}$ (Figure 3).

The rotor speed is faster than the aerodynamic optimum until the wind reaches $6.5 \mathrm{~m} / \mathrm{s}$. However, little energy is lost because little energy is available below $6.5 \mathrm{~m} / \mathrm{s}$. The amount of energy the machine captures below $6.5 \mathrm{~m} / \mathrm{s}$ is only $4.1 \%$ of the total energy output. A theoretical $25 \%$ aerodynamic efficiency improvement is possible below $6.5 \mathrm{~m} / \mathrm{s}$ if the machine is operated in variable speed mode throughout the low wind speeds, but this will yield only about .5\% additional energy capture for the assumed wind regime. 
This study assumed that the turbine with the CVT drive train began variable speed at $5.0 \mathrm{~m} / \mathrm{s}$. This compromise was made to reduce the range of ratios over which the CVT must operate. Starting at this speed results in a theoretical loss of less than $0.1 \%$ of the available energy compared to beginning the variable speed range at $3.0 \mathrm{~m} / \mathrm{s}$.

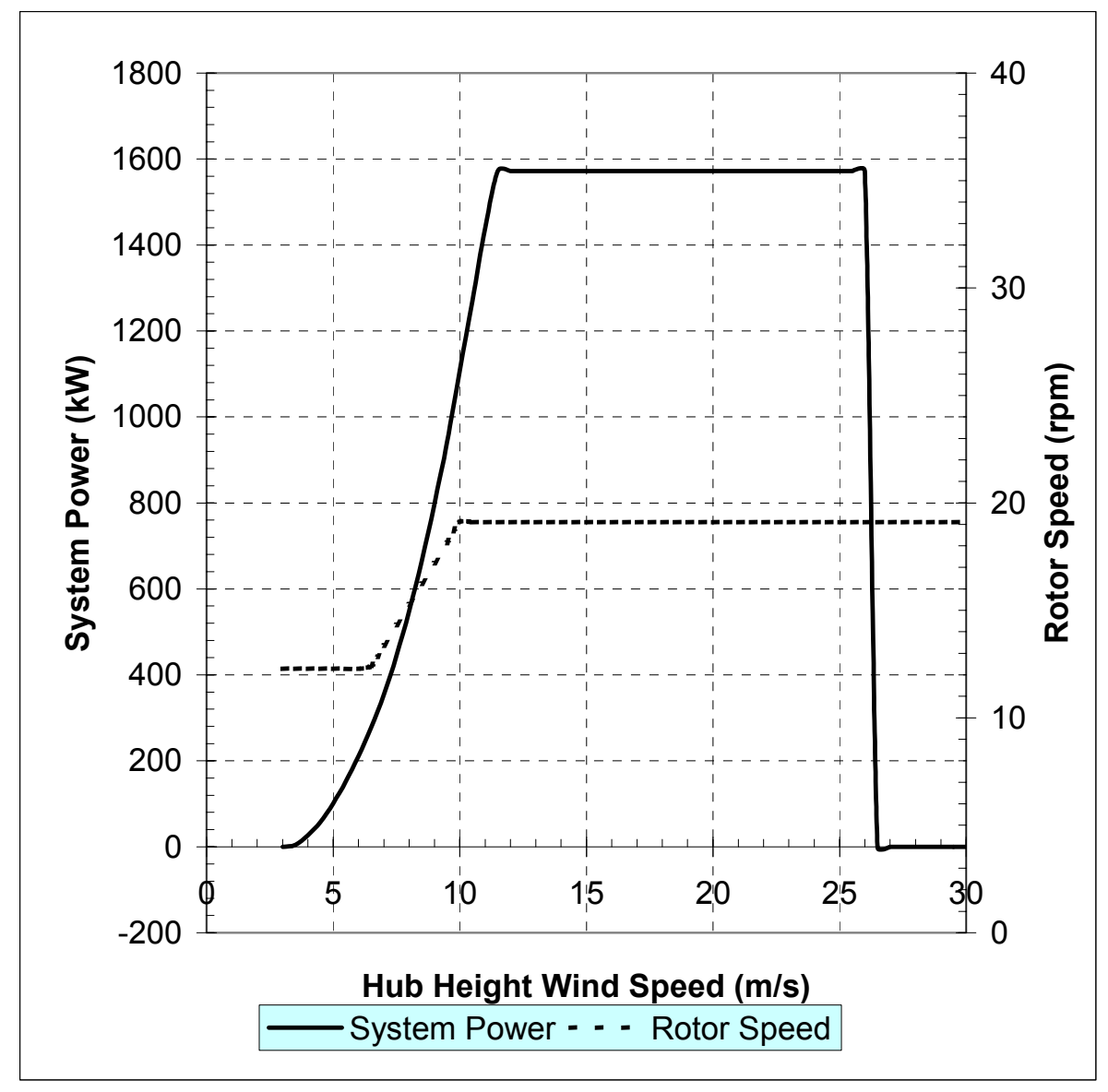

Figure 3. WindPACT power curve and rpm curve for a 1.5-MW turbine

A second advantage of a CVT is its potential to obtain variable speed with reliable and efficient PM generators or squirrel cage induction generators without maintenance-prone slip rings or expensive and relatively inefficient PE. A third advantage is that it is unlikely to infringe on the Kenetech patent on variable speed systems [4], which is now owned by GE Wind Energy.

\section{Cost of Energy Analyses}

\section{Method}

The COE for the CVT configurations was compared to results from the WindPACT Advanced Wind Turbine Drive Train Design Study. Because some drive train architectures are better suited to particular mainframe architectures, the WindPACT study contains two 
baseline turbines: a conventional modular mainframe design and an integrated mainframe design. Also presented in the WindPACT study is a PM design that uses a single stage gearbox. This design is used as a baseline with which to compare the PM CVT configurations. Figure 4 is a schematic of all three of these machines.

\section{Assumptions}

The Motion CVT is still an emerging technology and has not yet been built in the sizes necessary to handle the large torque loads generated by utility-scale wind turbines. Several assumptions were made regarding the costs of replacement, operations and maintenance, assembly, and testing. Generally, these costs were assumed to be equal to or slightly greater than those of the baseline turbines.

\section{Cost Models}

The WindPACT drive train study created detailed cost models for nine drive train configurations based on experience and vendor quotes. The cost estimates for the other turbine components were based on a cost model developed in the WindPACT Turbine Rotor Design Study [5]. The costs models were developed for wind turbine sizes .75 MW, 1.5 MW, and $3 \mathrm{MW}$. All calculations performed in this study assume a 1.5-MW wind turbine, which is the size most commonly installed at onshore locations.

An effort was made to create a cost estimate for the CVT drive train. However, the scale of the CVT necessary for use in a wind turbine is significantly larger than any Motion CVTs built to date. The weight data available from Motion Technologies were obtained from a $.056-\mathrm{kNm}$ CVT. A $1.5-\mathrm{MW}$ wind turbine produces roughly $932 \mathrm{kNm}$ at the low-speed shaft or $13 \mathrm{kNm}$ at the input for an 1800-rpm generator. It was decided that too large an extrapolation was required to estimate the mass of the CVT. Instead, the CVT was assumed to add $\$ 20,000$ to the cost of the gearboxes used in the WindPACT study. In addition, a sensitivity study was performed to determine the $\mathrm{COE}$ as a function of CVT capital cost.

\section{Performance Models}

The formula for the COE is calculated as

$\mathrm{COE}=(\mathrm{FCR} *$ Capital Cost + Replacement Cost $) /($ Annual Energy Capture $)+\mathrm{O} \& \mathrm{M}$ costs

Fixed charge rate (FCR) is used to distribute the capital cost and financing details over a period of time. The annual energy capture is estimated by convolving the wind turbine power curve with an assumed wind speed distribution, such as the curve in Figure 3. 

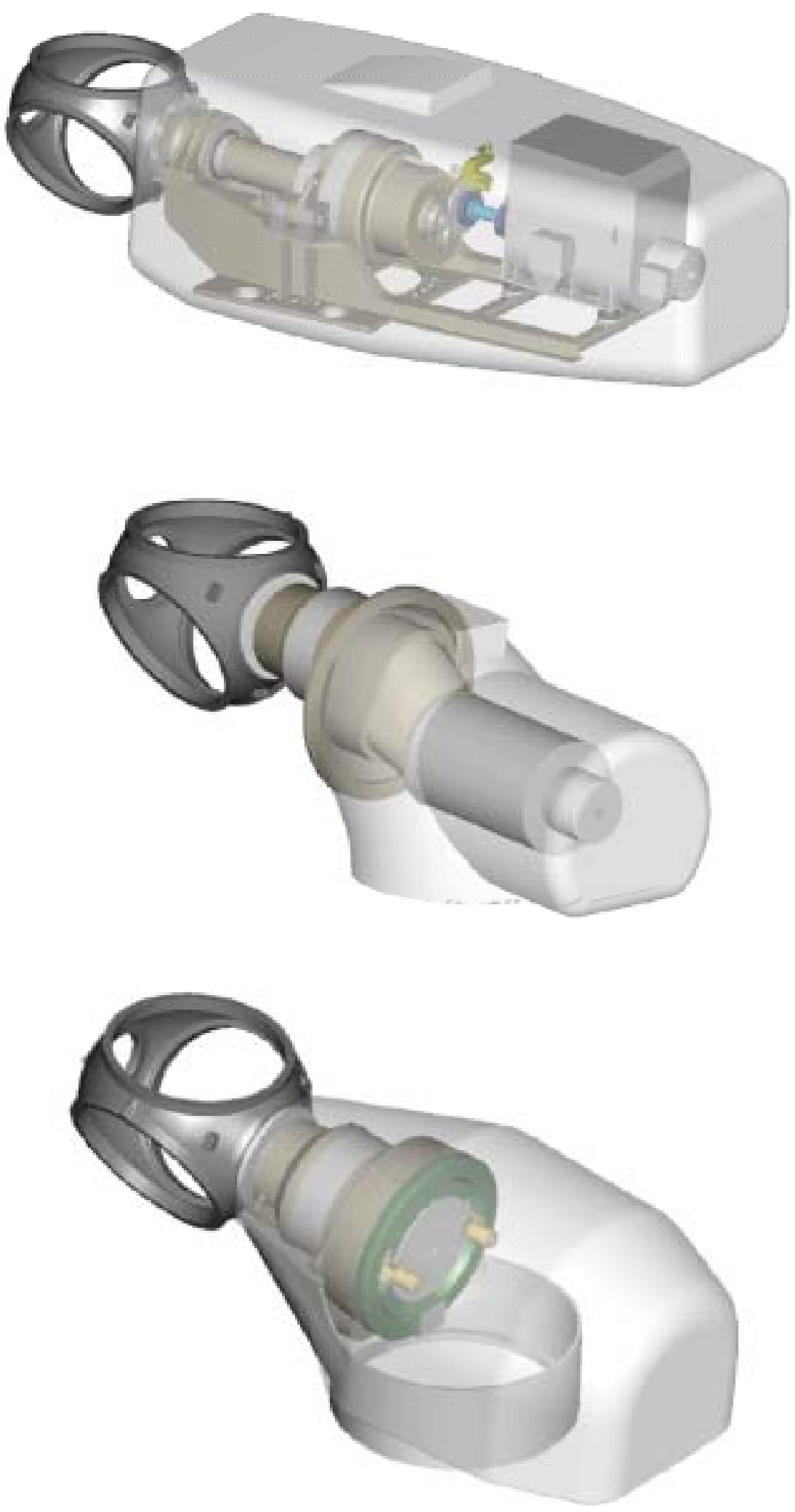

Figure 4. Modular, integrated, and PM baseline configurations 


\section{CVT Configurations}

Two generators - the squirrel cage induction generator and the synchronous PM generatorwere considered for use with the CVT. The advantages of the induction generator relative to the PM generator are:

- It has a lower capital cost.

- The slip provides some load absorption.

- It is widely available.

The advantages of a PM generator are:

- It is slightly more efficient.

- Its slow speed (many pole) designs permit the use of fewer geared stages.

\section{Using an Induction Generator with a CVT}

The induction generator in a wind turbine located in the United States typically spins nominally at $1200 \mathrm{rpm}(60 \mathrm{~Hz}$ with 6 poles) or $1800 \mathrm{rpm}$ ( $60 \mathrm{~Hz}$ with 4 poles). In the WindPACT baseline, the three-stage gearbox has a ratio of 72:1 and is used with a 6-pole generator. In this study, the CVT is assumed to replace the third stage of a three-stage gearbox when used with the induction generator. The first two stages are planetary stages as assumed in the WindPACT drive train study.

Three CVT configurations - standard operation, locked operation, and fixed carrier outputwere considered with the induction generator. In the standard operating mode, the CVT ratio changes to maximize aerodynamic efficiency of the rotor (maintain a TSR $=7$ ). The CVT efficiency used for this simulation was interpolated from data provided by Motion Technologies and is presented in Table 1.

Table 1. CVT Efficiency Data from Motion Technologies Inc.

\begin{tabular}{|c|c|}
\hline Slip Ratio & CVT Efficiency Data \\
\hline 0.44 & $84.2 \%$ \\
\hline 0.66 & $92.4 \%$ \\
\hline 0.71 & $94.0 \%$ \\
\hline 0.83 & $94.7 \%$ \\
\hline 0.93 & $95.4 \%$ \\
\hline 1 & $95.0 \%$ \\
\hline 1.14 & $95.5 \%$ \\
\hline 1.36 & $94.8 \%$ \\
\hline 1.57 & $93.8 \%$ \\
\hline 1.79 & $93.3 \%$ \\
\hline
\end{tabular}

Locked operation refers to a CVT operating mode in which the ball carrier is free to rotate with the discs and the balls are set at 1:1 (0 degrees tilt). In this mode, the drive train losses 
are confined primarily to the support bearings on the input and output shafts. This study assumes the CVT operates at $99.7 \%$ efficiency when locked.

The locked CVT mode could be used to improve drive train efficiency over a discrete region of the power curve. Over this region, the turbine would operate in a constant-speed mode (constant rotor rpm). The turbine would operate at the most efficient tip speed ratio at the center of the region but slightly off the aerodynamic optimum ratio at the edges of this region. However, if implemented properly, the increase in drive train efficiency should outweigh this small aerodynamic penalty.

The Excel solver was used to identify the region of the power curve over which to lock the CVT to maximize the energy produced. Generally, this region was centered just below the speed at which rated power occurs. This result is logical because this region is typically the location on the power curve in which wind turbines produce the most energy annually. Thus, the energy capture should be maximized if the drive train is arranged so that both the CVT and tip speed ratio are most efficient when centered on this point.

As with the standard operating CVT configuration, the gearboxes were assumed to use two primary stages of planetary gearing in addition to the CVT. The CVT was assumed to function as a standard CVT outside of the locked region. The control issues associated with integrating this configuration into the wind turbine power curve were not explored.

The third CVT configuration considered was termed the fixed-carrier configuration. In this configuration, the output disc is eliminated and becomes part of the stationary case. The balls roll along the ID of the case and the output is through the carrier that houses the balls. This design tends to be very efficient because the discs contact the balls/planets near their equator. Theoretically, the speed increase available for this CVT is unlimited. However, with this new technology there is an unknown physical limit.

The calculated COEs for the three squirrel cage configurations are presented in Table 2 . The reduction in $\mathrm{COE}$ relative to the integrated baseline turbine is $1.5 \%$ to $2.7 \%$. Figure 6 is a plot of the $\mathrm{COE}$ as a function of the drive train cost for the configuration with the lowest COE: the fixed-carrier configuration. 


\section{Table 2. Squirrel Cage CVT Results with an Integrated Mainframe}

\begin{tabular}{|c|c|c|c|c|}
\hline \multirow[b]{2}{*}{ Drive Train \& Nacelle } & $\begin{array}{l}\text { WindPACT 1.5MW } \\
\text { Integrated Baseline } \\
\text { Turbine }\end{array}$ & Standard & $\begin{array}{l}\text { Locking } \\
\text { CVT Config }\end{array}$ & $\begin{array}{l}\text { Fixed } \\
\text { Carrier } \\
\text { Output CVT }\end{array}$ \\
\hline & & & & \\
\hline Transmission & 120,000 & $\$ 140,000$ & $\$ 140,000$ & $\$ 140,000$ \\
\hline Support Structure & 21,000 & $\$ 21,000$ & $\$ 21,000$ & $\$ 21,000$ \\
\hline External Cooling & 3,000 & 3,000 & 3,000 & 3,000 \\
\hline Brake & 1,300 & 1,300 & 1,300 & 1,300 \\
\hline Coupling & 2,100 & 2,100 & 2,100 & 2,100 \\
\hline Nacelle Cover & 9,000 & 9,000 & 9,000 & 9,000 \\
\hline Generator & 60,000 & $\$ 42,000^{\circ}$ & $\$ 42,000$ & $\$ 42,000$ \\
\hline Power electronics & 61,800 & $\$ 17,000$ & $\$ 17,000$ & $\$ 17,000$ \\
\hline Substation VAR & NA & $\$ 12,000$ & $\$ 12,000$ & $\$ 12,000$ \\
\hline Transformer & 23,000 & $\$ 23,000$ & $\$ 23,000$ & $\$ 23,000$ \\
\hline Cable & 18,000 & $\$ 18,000$ & $\$ 18,000$ & $\$ 18,000$ \\
\hline Switchgear & 12,000 & $\$ 12,000$ & $\$ 12,000$ & $\$ 12,000$ \\
\hline Other & 25,000 & $\$ 25,000$ & $\$ 25,000$ & $\$ 25,000$ \\
\hline Drive train assemble \& test & 4,900 & 8,000 & 8,000 & 8,000 \\
\hline \multicolumn{5}{|l|}{ Turbine } \\
\hline Rotor & 248,000 & $\$ 248,000$ & $\$ 248,000$ & $\$ 248,000$ \\
\hline Yaw Drive \& Bearing & 16,000 & $\$ 16,000$ & $\$ 16,000$ & $\$ 16,000$ \\
\hline Control, Safety System & 7,000 & 7,000 & 7,000 & 7,000 \\
\hline Tower & 184,000 & $\$ 184,000$ & $\$ 184,000$ & $\$ 184,000$ \\
\hline $\begin{array}{l}\text { Turbine Manufacture's Overhead \& Profit } \\
\text { tower,rotor,and transformer }\end{array}$ & 108,330 & $\$ 100,020$ & $\$ 100,020$ & $\$ 100,020$ \\
\hline Balance of station & 358,000 & $\$ 358,000$ & $\$ 358,000$ & $\$ 358,000$ \\
\hline \multicolumn{5}{|l|}{ Figures of Merit } \\
\hline Total Turbine & $1,282,430$ & $\$ 1,246,420$ & $\$ 1,246,420$ & $\$ 1,246,420$ \\
\hline Drive Train component cost & 361,100 & $\$ 333,400$ & $\$ 333,400$ & $\$ 333,400$ \\
\hline Percenatge of baseline drive & $86 \%$ & $79 \%$ & $79 \%$ & $79 \%$ \\
\hline Annual net energy production & $5,590,000$ & $5,533,361$ & $5,587,521$ & $5,616,181$ \\
\hline Percentage of baseline & $100.0 \%$ & $99 \%$ & $100.0 \%$ & $100.5 \%$ \\
\hline Replacement costs--LRC & 5,100 & 5,100 & 5,100 & 5,100 \\
\hline O\&M (\$/yr) & 24,600 & 24,600 & 24,600 & 24,600 \\
\hline O\&M (\$/kWh) & 0.0044 & 0.0044 & 0.0044 & 0.0044 \\
\hline $\operatorname{COE}(\$ / k W h)=$ & 0.0296 & $\$ \quad 0.0292$ & $\$ 0.0290$ & $\$ 0.0288$ \\
\hline Percentage of baseline & $95.3 \%$ & $93.9 \%$ & $93.2 \%$ & $92.7 \%$ \\
\hline Reduction in COE compared to & $4.7 \%$ & $6.1 \%$ & $6.8 \%$ & $7.3 \%$ \\
\hline COE relative to integrated & $100.0 \%$ & $98.5 \%$ & $97.7 \%$ & $97.3 \%$ \\
\hline $\begin{array}{l}\text { Difference in COE relative to integrated } \\
\text { baseline }\end{array}$ & $0.0 \%$ & $1.5 \%$ & $2.3 \%$ & $2.7 \%$ \\
\hline
\end{tabular}




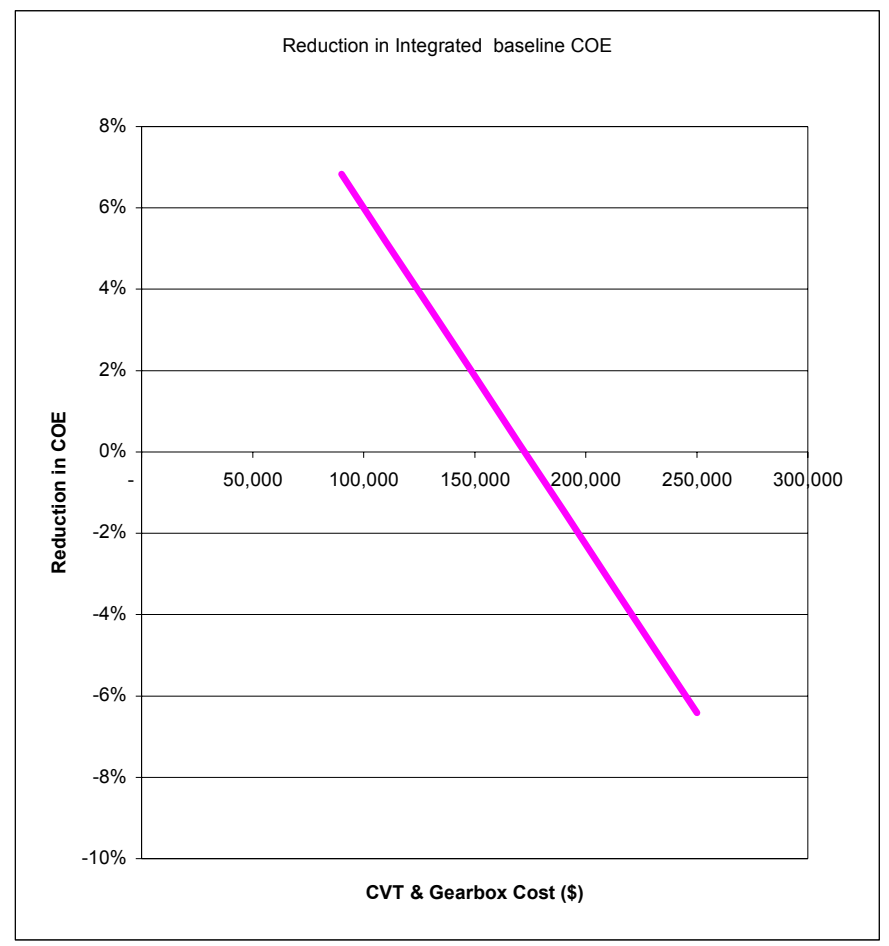

Figure 6. COE change for the fixed carrier CVT, with the squirrel cage generator
configuration as a function of drive train cost Using a Permanent Magnet Generator with a CVT

Permanent magnet synchronous generators have the advantages of being slightly more efficient (less than $2 \%$ ) than an induction generator and able to operate efficiently at low speeds. However, because synchronous generators have no slip, they must be decoupled from the grid to prevent dynamic loads from damaging the drive train. It may be possible to achieve this decoupling by actively controlling the CVT to increase the rotor speed during gusts. The energy in the gusts would be stored in the inertia of the rotor. The extent of the load mitigation for this control method would depend on the control limitations of the CVT. As a rough estimate, a synchronous generator would have to be controlled with bandwidth on the order of $60 \mathrm{~Hz}$ with a range of approximately $5 \%$. In contrast, because of slip, an induction machine could withstand slower controls (approximately $3 \mathrm{~Hz}$ ).

It appears possible that the CVT can be controlled quickly enough when used as the third stage. A generator input speed of $1800 \mathrm{rpm}$ equates to $30 \mathrm{rev} / \mathrm{s}(\mathrm{Hz})$, or $0.03 \mathrm{~s} / \mathrm{rev}$. Motion Technologies estimates it should take about one-tenth rev to make a ratio change of $5 \%$; thus ratio changes should be possible at a frequency of $300 \mathrm{~Hz}$. However, if the CVT is used in conjunction with a single-stage gearbox, the input speed can be expected to be approximately $1800^{\wedge} 2 / 3$, or $148 \mathrm{rpm}$. This equates to only $2.5 \mathrm{~Hz}$ or $25 \mathrm{~Hz}$ to make a ratio change of $5 \%$. Further investigation will be required to determine whether this rate is sufficient to adequately mitigate dynamic loads when using a single stage gearbox. 
Several additional concerns regarding the controller exist. One unanswered question pertains to the precision required by the CVT controller. The effects on energy capture and drive train life need to be explored as functions of controller precision. For example, how is the drive train life affected if the CVT provides a ratio of 1.10:1 instead of 1.05:1?

Another concern is durability. Turbines are typically designed to run approximately175,000 hours (nearly 20 years of continuous operation). Fatigue of the input and output discs is expected to be the primary concern. Other concerns relate to fatigue of the variator, the shift mechanism, and power rollers.

The COE results for three PM-CVT configurations are presented in Table 3. Figure 7 is a plot of the $\mathrm{COE}$ as a function of the transmission cost. Also considered were configurations using multiple stage gearboxes. However, all three configurations use a single-stage gearbox with the PM generator because that configuration led to the lowest COE, according to the assumptions of this study. However, this study assumes that the CVT cost is $\$ 20,000$ for each configuration. The higher torque levels that result from using the CVT with a single stage gearbox are likely to increase the cost of the CVT. Because of this uncertainty in CVT cost, a sensitivity study was performed to investigate the effect of transmission cost on COE (Figure 7). 


\section{Table 3. CVT Results with a PM Generator, Single Stage Gearbox, and Integrated}

Mainframe

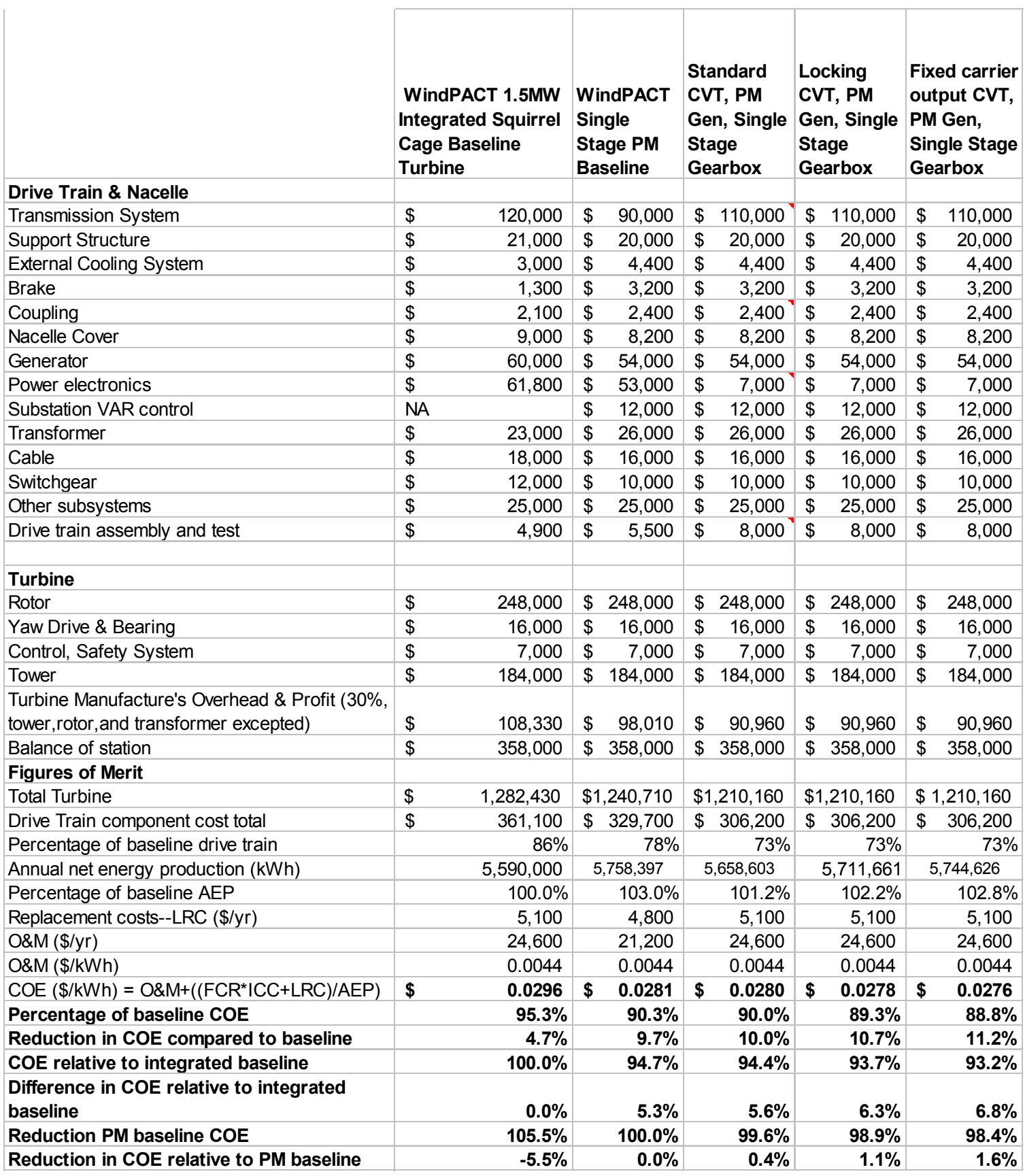




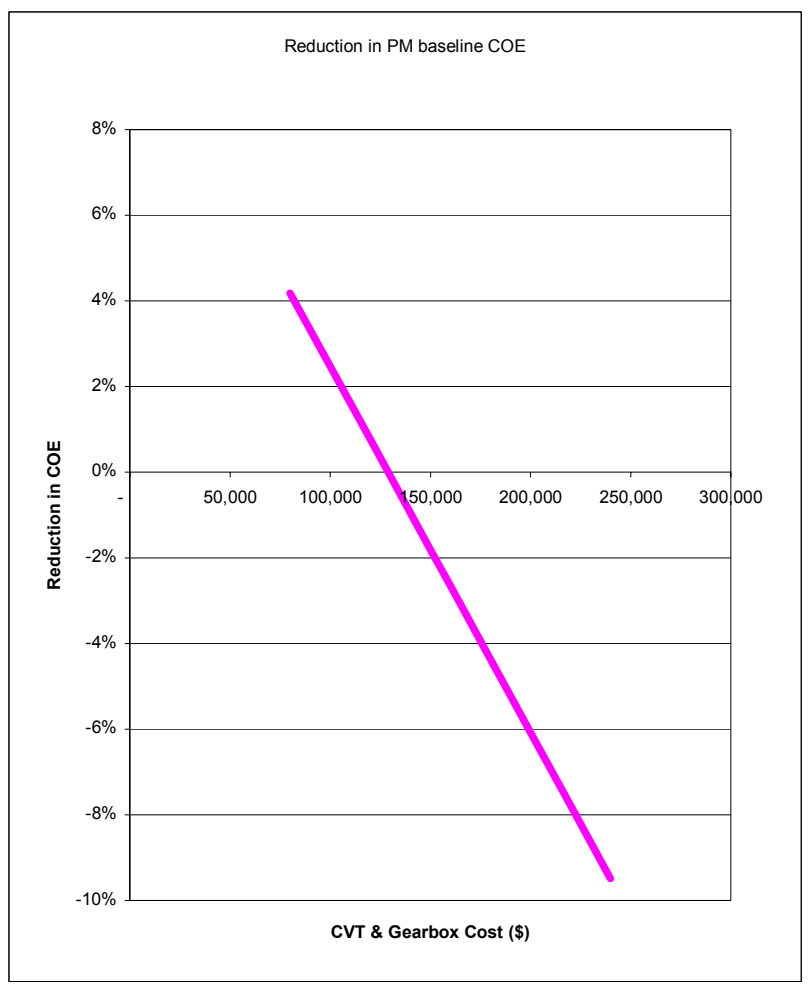

Figure 7. Reduction in COE for the fixed carrier output, PM, CVT configuration as a function of transmission cost

\section{Conclusions}

Permanent magnet and squirrel cage induction generators were considered for use with three CVT configurations. Depending on the cost to manufacture the Motion Technologies CVT, the technology can be cost competitive with a conventional variable speed drive train.

With the squirrel cage generator, the fixed carrier configuration results in a COE $2.7 \%$ below the integrated baseline turbine. Using the PM generator with the fixed carrier CVT configuration results in a COE reduction of $6.8 \%$ below that for the integrated baseline turbine when a CVT cost of $\$ 20,000$ is assumed and $1.6 \%$ below the WindPACT PM, medium speed, drive train COE.

The CVT configurations result in lower capital costs than the WindPACT machines, in part because the CVT configurations use less PE and can operate at higher drive train efficiencies. The ability of the CVT to broaden the range of variable speed operation could increase the amount of energy produced. However, in general this increase in energy production was only on the order of $.5 \%$ and is reflected in the COE results in this report.

\section{Future Work}

A detailed cost model of a 1.5-MW CVT needs to be created to refine the COE analysis. In addition, wind turbine simulations are needed to assess CVT's effect on loads. The behavior of the drive train will affect how the turbine responds to wind gusts and the load spectrum applied to the machine. 


\section{References}

1. Poore, R.; Lettenmaier, T. Alternative Design Study Report: WindPACT Advanced Drive Train Designs Study. NREL/SR-500-33196. Work performed by Global Energy Concepts LLC, Kirkland, Washington. Golden, CO: National Renewable Energy Laboratory, August 2003. http://www.nrel.gov/docs/fy03osti/33196.pdf.

2. Carlin, P.W.; Laxson, A.S.; Muljadi, E.B. The History and State of the Art of VariableSpeed Wind Turbine Technology. NREL/TP-500-28607. Golden, CO: National Renewable Energy Laboratory, February 2001. http://www.nrel.gov/docs/fy01osti/28607.pdf.

3. Hau, E. Windturbines: Fundamentals, Technologies, Application and Economics. New York: Springer-Verlag Telos, 1999; pp. 272-277.

4. Richardson, R.; Erdman, W. U.S. Patent No. 5,083,039, 21 January 1992.

5. Smith, K. WindPACT Turbine Design Scaling Studies Technical Area 2: Turbine, Rotor, and Blade Logistics. NREL/SR-500-29439. Work performed by Global Energy Concepts LLC, Kirkland, Washington. Golden, CO: National Renewable Energy Laboratory, June 2001. http://www.nrel.gov/docs/fy01osti/29439.pdf. 


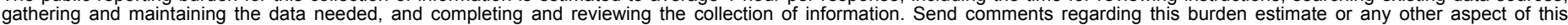

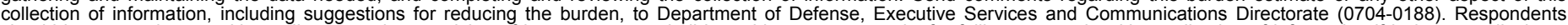

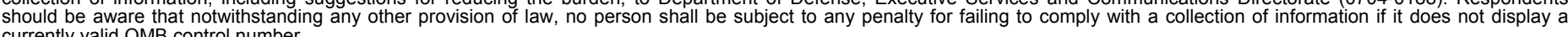

PLEASE DO NOT RETURN YOUR FORM TO THE ABOVE ORGANIZATION.
1. REPORT DATE (DD-MM-YYYY) 09-2004
4. TITLE AND SUBTITLE
Motion Technologies CRADA CRD-03-130: Assessing the Potentia of a Mechanical Continuously Variable Transmission

3. DATES COVERED (From - To)

5a. CONTRACT NUMBER

DE-AC36-99-GO10337

5b. GRANT NUMBER

5c. PROGRAM ELEMENT NUMBER

5d. PROJECT NUMBER

NREL/TP-500-36371

5e. TASK NUMBER

WER4.3202

5f. WORK UNIT NUMBER

7. PERFORMING ORGANIZATION NAME(S) AND ADDRESS(ES)

National Renewable Energy Laboratory

1617 Cole Blvd.

Golden, CO 80401-3393

9. SPONSORING/MONITORING AGENCY NAME(S) AND ADDRESS(ES)

\section{PERFORMING ORGANIZATION REPORT NUMBER \\ NREL/TP-500-36371}

10. SPONSOR/MONITOR'S ACRONYM(S) NREL

11. SPONSORING/MONITORING AGENCY REPORT NUMBER

12. DISTRIBUTION AVAILABILITY STATEMENT

National Technical Information Service

U.S. Department of Commerce

5285 Port Royal Road

Springfield, VA 22161

\section{SUPPLEMENTARY NOTES}

14. ABSTRACT (Maximum 200 Words)

This report summarizes the results of a cooperative research and development agreement (CRADA) between the National Renewable Energy Laboratory (NREL) and Motion Technologies LLC. The purpose of the CRADA is to assess the usefulness of a continuously variable transmission (CVT) for wind turbine applications. The CVT considered is capable of rapid ratio changes and may be directly applicable to variable speed wind turbine designs. This approach potentially offers a less expensive mechanical alternative to the use of power electronics (PE) currently used in large and small machines for variable speed operation.

According to Motion Technologies, the CVT is the first continuously variable transmission that is scalable to the torque capacities required in large wind turbine applications. The CVT technology was examined for potential economic and performance benefits when integrated into conventional wind turbine designs. This report is the first step in assessing the practicality of using CVT technology in variable speed wind turbines.

15. SUBJECT TERMS

wind energy; wind turbine; CRADA; CVT; continuously variable transmission; Motion Technologies

\begin{tabular}{l} 
16. SECURITY CLASSIFICATION OF: \\
\begin{tabular}{|l|l|l|}
\hline $\begin{array}{l}\text { a. REPORT } \\
\text { Unclassified }\end{array}$ & b. ABSTRACT & c. THIS PAGE \\
& Unclassified & Unclassified \\
\hline
\end{tabular} \\
\hline
\end{tabular}

\begin{tabular}{l|l} 
17. LIMITATION \\
OF ABSTRACT \\
UL
\end{tabular}

19a. NAME OF RESPONSIBLE PERSON

19b. TELEPONE NUMBER (Include area code) 